\title{
Mekanisme/Model Penguatan Komposit Bermatrik Logam dengan Berpenguat Partikel
}

\author{
Muhammad Budi Haryono ${ }^{1}$, Wikan Budi Utami ${ }^{2}$ \\ ${ }^{1}$ Program Studi Teknik Mesin, Universitas PGRI Semarang \\ Jl. Sidodadi Timur Nomor 24-Dr.Cipto, Karangtempel, Semarang, 50125 \\ ${ }^{2}$ Program Studi Pendidikan Matematika, Universitas Pancasakti Tegal \\ Jl. Halmahera KM.1. Tegal, 52121 \\ E-mail: haryono.upstegal@gmail.com
}

\begin{abstract}
The use of particles as reinforcing material from metal composites has the advantage of increasing the strength and modulus of the composite. The effect of the strengthening mechanism is due to the presence of particle reinforcement on the mechanical properties of the composite. The strengthening mechanism in composites discussed as follows: the strengthening model at the macro level is the law of mixtures, and the nano-level strengthening model is the dislocation reinforcement. The nano-level strengthening model based on dislocation reinforcement is divided into the Orowan model, the forest hardening model, the elastic peg model, and the punching model to explain well the reinforcement observed in MMC (metal matrix composites) with particle strength. CTE mismatch strain is the primary key to increase the yield stress on the composite
\end{abstract}

Keywords: Particle, composite, strengthening mechanism.

\begin{abstract}
Abstrak
Penggunaan partikel sebagai bahan penguat dari komposit logam memiliki keunggulan untuk meningkatkan kekuatan dan modulus dari komposit. Pengaruh dari mekanisme penguatan disebabkan oleh adanya penguat partikel pada sifat mekanik dari komposit. Mekanisme penguatan pada komposit didiskusikan menjadi: model penguatan pada level macro adalah law of mixtures, dan pada model penguatan level nano yaitu penguatan dislokasi. Pada model penguatan level nano yang berbasis penguatan dislokasi terbagi menjadi model Orowan, model forest hardening, model elastic peg, dan model punching untuk menjelaskan dengan baik penguatan yang diamati pada MMC (metal matrix composites) berpenguat partikel. Regangan CTE mismatch merupakan kunci utama untuk peningkatan tegangan luluh pada komposit.
\end{abstract}

Kata kunci: Partikel, komposit, mekanisme penguatan.

\section{PENDAHULUAN}

Komposit bermatriks logam $(M M C)$ dengan penguat partikel secara luas digunakan dalam bidang penerbangan, otomotif dan industri disebabkan memiliki sifat yang sangat baik seperti tingginya kekuatan dan kekakuan [1-4].

Mekanisme penguat dan memprediksi kekuatan luluh yang sangat penting untuk dipahami untuk memproduksi komposit bermatriks logam berkinerja tinggi, dan menghasilkan komponen dengan kualitas tinggi. Banyak penelitian dilakukan untuk mengklarifikasi mekanisme penguatan PRMMC dalam beberapa decade terakhir. Beberapa mekanisme seperti perpindahan beban dari matriks ke partikel, thermal mismatch strengthening, hellpatch strengthening, Orowan strengthening, dan work hardening. Mekanisme penguatan tersebut telah dipercaya bertanggung jawab atas kekuatan mekanik PRMMC yang tinggi $[5,6]$.

Antarmuka penguat/matriks terbentuk selama proses pembuatan oleh penguat dan matriks, seperti reaksi kimia dan difusi dari elemen [7, 8]. Sifat mekanik dari PMMC ditentukan oleh bentuk, model distribusi, volume fraksi partikel, dan karakteristik dari matriks, dan partikel [9-11]. Antarmuka partikel/matriks dibentuk dengan penambahan partikel, tetapi pada saat yang sama, partikel dapat mempengaruhi struktur mikro pada matriks dan menghasilkan berbagai mekanisme penguat, keduanya mempengaruhi sifat mekanik dari komposit $[9,13,14]$.

Penguat partikel keramik sering kali digunakan sebagai bahan penguat untuk MMC. Mereka memiliki keunggulan untuk meningkatkan kekuatan dan modulus, tetapi memiliki kerugian dikarenakan menurunkan sifat keuletan secara signifikan. Keuletan dapat dijaga dengan memperhatikan beberapa hal sebagai berikut: (1) adhesi antarmuka yang baik antara partikel penguat dan matriks; (2) tidak adanya cacat seperti lubang dan retakan baik matriks maupun pada pertikel penguat; (3) reaksi antarmuka; dan (4) lapisan amorf [7, 8]. 
Ringkasan ini bertujuan untuk memberikan pemahaman tentang mekanisme penguatan $M M C$ berpenguat partikel yang berkontribusi sangat besar terhadap peningkatan kekuatan mekanik pada komposit.

\section{TINJAUAN PUSTAKA}

\section{Model Penguatan}

Model penguatan pada $M M C$ berpenguat partikel terbagi menjadi dua; (1) model hukum campuran (law of mixtures); dan (2) model dislokasi [15].

\section{Law of mixtures model}

Mempertimbangkan komposit yang terdiri dari penguat dan matriks, dan mengalami tegangan yang diterapkan $\sigma_{0}$. Integral volume dari tegangan pada keseluruhan komposit dapat dirumuskan sebagai berikut

$$
\int_{c} \sigma_{c} d v=\int_{m} \sigma_{m} d v+\int_{f} \sigma_{f} d v
$$

dimana $\int$ menunjukan domain dari integral volume dan $\mathrm{dv}$ mendefinisikan volume dari elemen. $\sigma_{c}, \sigma_{m}$, dan $\sigma_{f}$ diambil sebagai nilai rata-rata dari volume, selanjutnya persamaan (1) disederhanakan menjadi

$$
v_{c} \sigma_{c}=v_{m} \sigma_{m}+v_{f} \sigma_{f}
$$

Membagi persamaan (2) dengan $v_{c}$ dan memperkenalkan fraksi volume dari setiap fasa.

$$
\begin{gathered}
c_{m}=v_{m} / v_{c} \\
c_{f}=v_{f} / v_{c} \\
c_{m}+c_{f}=1
\end{gathered}
$$

diperoleh

$$
\sigma_{c}=c_{m} \sigma_{m}+c_{f} \sigma_{f}
$$

Persamaan (4) merupakan persamaan law of mixtures dalam hal aliran tegangan yang meliputi tegangan luluh. Tegangan pada komposit (persamaan 1) dapat didekomposisi kedalam keseragaman tegangan (diterapkan) dan tegangan yang terganggu yang disebabkan keberadaan penguat. Oleh karena itu, integral volume pada persamaan (1) dapat disederhanakan menjadi

$$
\int_{c} \sigma_{c} d v=\int_{c}\left(\sigma_{0}+\sigma_{d}\right) d v
$$

Dikarenakan integral volume dari tegangan yang terganggu didalam seluruh domain komposit lenyap, persamaan (5) setara dengan $v_{c} \sigma_{0}$, mengahasilkan

$$
\sigma_{0}=\sigma_{c}
$$

dianggap sebagain "tegangan komposit". Keakuratan tegangan dari komposit $\sigma_{c}$ diberikan oleh persamaan (4) tergantung dengan hasil kalkulasi $\sigma_{m}$ dan $\sigma_{f}$. Evaluasi keakuratan dari $\sigma_{m}$ dan $\sigma_{f}$ melibatkan analisis tegangan dimensi tiga seperti metode Eshelby. Tegangan rata-rata dari masing-masing fasa dapat selajutnya diperkirakan sebagai

$$
\begin{gathered}
\sigma_{m}=E_{m} e \\
\sigma_{f}=E_{f} e \\
\sigma_{c}=E_{c} e
\end{gathered}
$$

memasukan persamaan (7) kedalam (4) memberikan kekakuan komposit $E_{c}$ yang dinyatakan oleh law of mixtures;

$$
E_{c}=c_{m} E_{m}+c_{f} E_{f}
$$

\section{Model dislokasi}

Model disloksi awalnya dibangun untuk memprediksi tahap kedua dari kurva teganganregangan dari persebaran partikel penguat. Model penguatan dari partikulat dapat digolongkan menjadi: (i) model Orowan, (ii) forest hardening model, (iii) elastic peg model, dan (iv) punching model.

\section{(i) Model orowan}

Model penguatan Orowan berasal dari interaksi antara partikel dan dislokasi [16]. Diasumsikan bahwa penguatan dislokasi dan penguatan Orowan terjadi didaerah yang sama. Kekuatan luluh dalam pergeseran dari penyebaran partikel penguat $\tau_{y}$ biasanya digunakan dalam persamaan tegangan Orowan, Gambar 1.

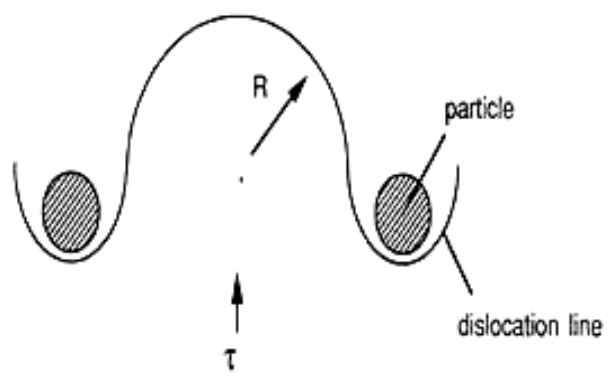

Gambar 1. Model orowan

$$
\tau_{y}=\alpha \frac{G b}{R}
$$

dimana $G$ dan $b$ merupakan modulus geser dan besaran vektor Burgers pada matriks logam, dan $\mathrm{R}$ merupakan radius kelengkungan dari dilokasi, dan kisaran konstan dari $\alpha$ berkisar 0.5 hingga 1.0. Formula Ashby's untuk $\tau_{y}$ sebagai berikut

dengan demikian, tegangan yang diterapkan dapat 


$$
\begin{gathered}
\tau_{y}=\frac{1}{1.18} \frac{2 A^{\prime}}{b \bar{D}} \quad \text { untuk dislokasi tepi } \\
\tau_{y}=\frac{1}{1.18} \frac{2 A^{\prime}}{b \bar{D}} \frac{1}{(1-v)} \quad \text { untuk dislokasi skrup }
\end{gathered}
$$

dimana

$$
\begin{gathered}
\overline{\mathrm{D}}=\frac{1}{\sqrt{N_{S}}} \\
A^{\prime}=\frac{G_{m} b^{2}}{4 \pi} \ln \left(\frac{d}{r_{0}}\right)
\end{gathered}
$$

$r_{0}$ merupakan the inner-cut off radius, biasanya digunakan $2 \mathrm{~b}$, dan $\mathrm{v}$ merupakan poisson's ratio dari matriks logam. Dari formula diatas $\tau_{y}$ meningkat dengan berkurangnya ukuran partikel.

\section{(ii) Forest hardening model}

Ebeling dan Ashby menunjukan Sebagian besar data eksperimen pada menengah (beberapa persen) hingga regangan plastik yang besar mengikuti hubungan tegangan geser/regangan geser [17].

$$
\tau=\tau_{y}+\eta \mathrm{G} \sqrt{\frac{b c_{f} \gamma}{d}}
$$

dimana $\tau$ dan $\gamma$ digunakan pada tegangan geser dan regangan plastik. G dan B merupakan modulus geser dan vektor Burgers dari matriks logam, $c_{f}$ dan d merupakan fraksi volume dan mean diameter dari partikel. $\eta$ adalah konstanta dimensionless (0.24 \pm 0.04$)$. Tegangan work-hardening $\tau-\tau_{y}$ proporsional untuk $\sqrt{\gamma}$ yaitu permulaan dari prediksi linear work-hardening dengan permodelan elastic peg. Ketergantungan akar kuadrat pada regangan geser dengan mengusulkan mekanisme relaksasi dari besarnya regangan misfit pada permukaan matrikspartikel, hal tersebut meningkat dengan meningkatnya regangan plastik geser. Mekanisme relaksasi merupakan meninju loop dislokasi sepanjang slip planes sekunder, yang berinteraksi dengan garis dislokasi padaa slip planes utama yang berkontribusi pada penyebaran partikel.

\section{(iii) Elastic peg model}

Tanaka dan Mori memperkenalkan elastic peg model berdasarkan mekanik contimum [18]. Loop dislokasi mewakili regangan misfit antara partikel elastic dan deformasi plastik dari matriks dan disebut "transformation strain" didefinisikan didalam partikel. Tanaka dan Mori memprediksi stress $\tau_{y}$ dan work-hardening $h$ pada MMC sebagai berikut:

$$
\sigma_{0}=\sigma_{y}+h e_{p}
$$

dimana

$\sigma_{0}$ dan $e_{p}$ mendefinisikan tegangan dan regangan plastic, dan h menerangkan modulus tangen, $E_{T}$.

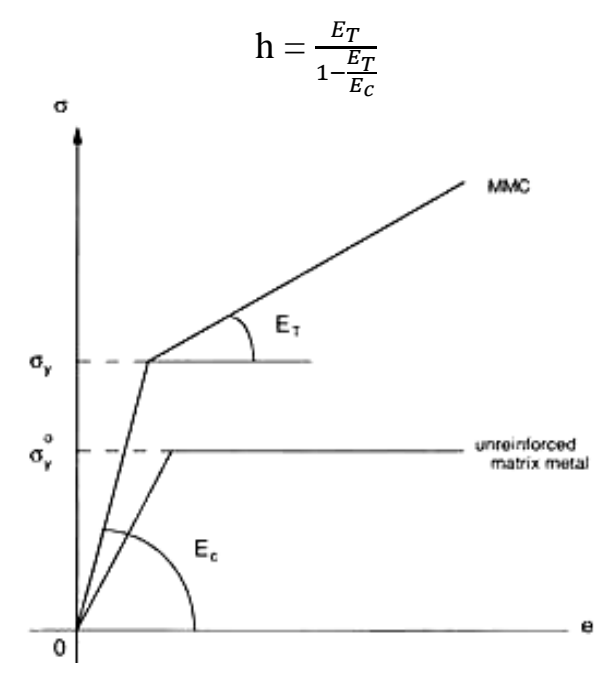

Gambar 2. Kurva tegangan-regangan pada MMC dengan dan tanpa penguat

\section{(iv) Punching model}

Arsenaullt dan Shi mempelajari the punching of dislocation loops dari partikel yang sama dalam sebuah $M M C$ berpenguat partikel dari sudut pandang geometri [19]. Rata-rata kepadatan dislokasi dalam matriks sebagai berikut:

$$
\mathrm{P}=\frac{A c_{f} e_{T}}{b\left(1-c_{f}\right)} \frac{1}{t}
$$

dimana $e_{T}$ merupakan regangan CTE misfit, $\mathrm{t}$ merupakan ukuran kecil dati $\mathrm{t}_{1}, \mathrm{t}_{2}$, dan $\mathrm{t}_{3}$ merupakan faktor geometri yang diambil mengikuti ukuran tergantung pada ukuran filler.

$\mathrm{A}=4$ untuk dimensi 1 , sangat kecil dibandingkan dengan dua yang lain dari $\mathrm{t}_{1}$

$\mathrm{A}=8$ untuk platelet dengan aspek rasio 2

$\mathrm{A}=10$ untuk fiber pendek dengan aspek rasio 2

$A=12$ untuk partikel, $t_{1}=t_{2}=t_{3}$

Gambar 3. menunjukan dimensi dari partikel yang sama yang ditandai dengan $\mathrm{t}_{1}, \mathrm{t}_{2}$, dan $\mathrm{t}_{3}$

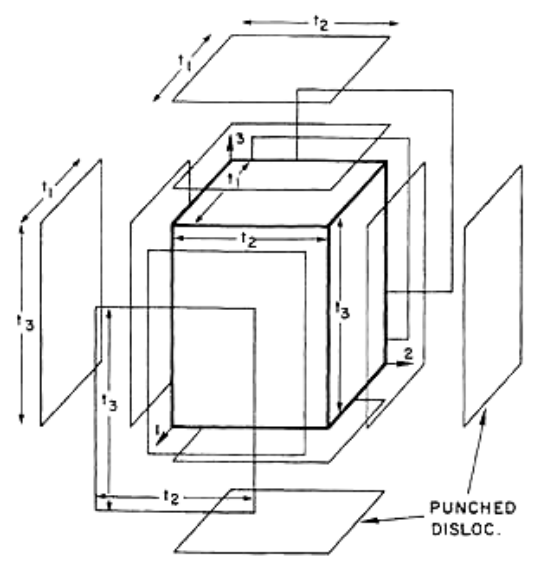

Gambar 3. Model analisis yang digunakan untuk 
punching of prismatic dislocation loops menjadi CTE misfit yang relaks pada MMC dengan penguat partikel dipermukaan.

Setelah $\bar{p}$ dihitung, peningkatan pada laju tengangan $\left(\Delta \sigma_{C T E}\right)$ disebabkan oleh regangan CTE misfit bisa diestimasikan sebagai berikut;

$$
\Delta \sigma_{C T E}=\gamma \mathrm{Gb} \sqrt{p}
$$

dimana $\gamma$ merupakan kontanta dari order dari 1, G dan $b$ merupakan modulus shear dan vector Burgers dari matriks logam.

\section{Kontribusi Penguat Partikel Pada Sifat Mekanik Komposit}

Komposit bermatriks besi dengan berpenguat partikel TiC yang diproduksi dengan pengecoran. Peningkatan kekuatan tarik dan kekuatan luluh terjadi seiring penambahan berat $\mathrm{TiC}$ sebagai penguat. Kekuatan tarik naik dari $656 \mathrm{MPa}(0.1 \mathrm{wt} \%$ TiC) menjadi $656 \mathrm{MPa}(0.5 \mathrm{wt} \% \mathrm{TiC})$ [20]. Pengaruh partikel TiC+TiB terhadap peningkatan kekuatan matriks aluminium yang diproduksi dengan SPS. Penggunaan TiC+TiB dapat meningkatan kekerasan dari $37 \mathrm{Hv}$ (tanpa penguat) menjadi $87 \mathrm{Hv}$ dengan penggunaan $20 \%$ penguat partakel [21]. Zhou Y memproduksi komposit berpenguat $\mathrm{TiC}$ dengan matriks Al-Si. Kekuatan tarik meningkat dari $398 \mathrm{MPa}$ (tanpa penguat) menjadi 578MPa dengan penambahan 1 wt\% TiC, tetapi kekuatan menurun menjadi $313 \mathrm{MPa}$ dengan peningkatan $2.5 \mathrm{wt} \% \mathrm{TiC}$ [22].

\section{KESIMPULAN}

Dari hasil ringkasan diatas dapat disimpulkan bahwa hasil numerik (kekuatan material) dari komposit merupakan efek dari ikatan penguat partikel/matriks dan mekanisme penguatan yang sangat baik oleh keduanya. Peningkatan modulus elastisitas dan kekuatan tarik dari sebuah komposit erat terait dengat mekanisme penguatan setelah dilakukan penambahan penguat partikel pada komposit. Namun seiring dengan peningkatan penggunaan volume fraksi dari penguat partikel pada komposit dapat menurunkan sifat mekanik dari komposit tersebut.

\section{DAFTAR PUSTAKA}

[1] Y. Su et al., 2014, "Composite structure modeling and mechanical behavior of particle reinforced metal matrix composites," Mater. Sci. Eng. A, vol. 597, pp. 359-369.

[2] R. A. Varin, 2002, "Intermetallic-reinforced light-metal matrix in-situ composites,"
Metall. Mater. Trans. A Phys. Metall. Mater. Sci., vol. 33, no. 1, pp. 193-201.

[3] T. I. B. A.- Composites, 2017, "Influence of Tib 2 Particles on Aging Behavior of inSitu," no. August, pp. 20-25.

[4] G. CHEN, J. WAN, N. HE, H. ming ZHANG, F. HAN, and Y. min ZHANG, 2018, "Strengthening mechanisms based on reinforcement distribution uniformity for particle reinforced aluminum matrix composites," Trans. Nonferrous Met. Soc. China (English Ed., vol. 28, no. 12, pp. 2395-2400.

[5] W. S. Miller, and F. J. Humphreys, 1990, "Strengthening mechanisms in particulate metal matrix composites," Scripta metallurgica et materialia, vol.25, pp. 33-38.

[6] N. M. Chelliah, H. Singh, and M. K. Surappa, 2017, "Microstructural evolution and strengthening behavior in in-situ magnesium matrix composites fabricated by solidification processing," Mater. Chem. Phys., vol. 194, pp. 65-76.

[7] S. J. Wang, G. Q. Wu, Z. H. Ling, and Z. Huang, 2009, "Microstructure and mechanical properties of YAl2 reinforced MgLiAl composite," Mater. Sci. Eng. A, vol. 518, no. 1-2, pp. 158-161.

[8] S. J. Wang, G. Q. Wu, R. H. Li, G. X. Luo, and Z. Huang, 2006, "Microstructures and mechanical properties of 5 wt.\% Al2Yp/MgLi composite," Mater. Lett., vol. 60, no. 15, pp. 1863-1865.

[9] W. Xu, X. Wu, T. Honma, S. P. Ringer, and K. Xia, 2009, "Nanostructured Al-Al2O3 composite formed in situ during consolidation of ultrafine $\mathrm{Al}$ particles by back pressure equal channel angular pressing," Acta Mater., vol. 57, no. 14, pp. 4321-4330.

[10] K. Tohgo, Y. Itoh, and Y. Shimamura, 2010, "A constitutive model of particulatereinforced composites taking account of particle size effects and damage evolution," Compos. Part A Appl. Sci. Manuf., vol. 41, no. 2, pp. 313-321.

[11] X. Deng and N. Chawla, 2006 "Modeling the effect of particle clustering on the mechanical behavior of $\mathrm{SiC}$ particle reinforced $\mathrm{Al}$ matrix composites," J. Mater. Sci., vol. 41, no. 17, pp. 5731-5734.

[12] L. J. Huang, L. Geng, and H. X. Peng, 2015 "Microstructurally inhomogeneous composites: Is a homogeneous reinforcement distribution optimal?," Prog. Mater. Sci., vol. 71, pp. 93-168.

[13] R. D. Evans and J. D. Boyd, 2003, "Nearinterface microstructure in a SiC/Al 
composite," Scr. Mater., vol. 49, no. 1 SPEC., pp. 59-63.

[14] J. C. Shao, B. L. Xiao, Q. Z. Wang, Z. Y. Ma, and K. Yang, 2011, "An enhanced FEM model for particle size dependent flow strengthening and interface damage in particle reinforced metal matrix composites," Compos. Sci. Technol., vol. 71, no. 1, pp. 3945.

[15] M. Taya, 1991, "Strengthening mechanism of metal matrix composite," Materials Transactions, vol. 32, pp. 1-19.

[16] G. M. Rassweiler, and W. L. Grube, 1959, "E.Orowan: Internal stresses and fatigue in metals," Elsevier Sci, pp. 59-80.

[17] P. Taylor and M. F. Ashby, 2012, "Work hardening of dispersion- hardened crystals,", pp. 37-41, 2006.

[18] O. F. Crystals and B. Y. 1970, Nondeforming, "Particles and," Arbeit.

[19] R. J. Arsenault and N. Shi, 1986, "Dislocation generation due to differences between the coefficients of thermal expansion," Mater. Sci. Eng., vol. 81, no. C, pp. 175-187.

[20] S. M. Hong, E. K. Park, J. J. Park, M. K. Lee, and J. Gu Lee, 2015, "Effect of nano-sized TiC particle addition on microstructure and mechanical properties of SA-106B carbon steel," Mater. Sci. Eng. A, vol. 643, pp. 3746.

[21] M. Hadian, H. Shahrajabian, and M. Rafiei, 2019, "Mechanical properties and microstructure of $\mathrm{Al} /(\mathrm{TiC}+\mathrm{TiB} 2$ ) composite fabricated by spark plasma sintering," Ceram. Int., vol. 45, no. 9, pp. 12088-12092.

[22] Y. Zhou, S. Wen, C. Wang, L. Duan, Q. Wei, and Y. Shi, 2019 "Effect of TiC content on the Al-15Si alloy processed by selective laser melting: Microstructure and mechanical properties," Opt. Laser Technol., vol. 120, no. July, p. 105719. 